\title{
Pogo Stick Programs Provide Physical and Psychological Benefits to Children
}

\author{
Jo M. Welch, Nichelle B. Hubley, Angela J. Stewart \\ Department of Kinesiology, School of Health and Human Performance, Dalhousie University, \\ Halifax, Canada \\ Email: jo.welch@dal.ca
}

Received November $17^{\text {th }}, 2011$; revised December $20^{\text {th }}, 2011$; accepted December $30^{\text {th }}, 2011$

\begin{abstract}
Novel methods of adding vigorous exercise to physical education classes or after school programs could boost physical and psychological well-being in children. We explored the use of pogo stick classes in two cohorts of 10 - 11 years old children. Both interventions consisted of two, one-hour sessions per week for six weeks. Attendance at these after-school sessions was high (Study 1, 82\%; Study 2, 95\%). Study 1 tested the efficacy of a pogo class in sports-active children aged 10 - 11 years from a community adjacent to a university. They were tested before and after the intervention for balance using a stabilometer, for leg power using jump height, and for $\mathrm{VO}_{2} \mathrm{max}$ using the Leger $20 \mathrm{~m}$ shuttle run. Means of pre and post intervention measures were compared using paired $t$-tests. Balance improved $(\mathrm{p}=0.001)$ while $\mathrm{VO}_{2}$ max and leg power remained consistent. Study 2 tested the ability of pogo classes to improve self-esteem in girls who did not participate in sports and resided in a low socio-economic urban area. Before and after the intervention they completed the Harter Self-Perception Profile. Self-assessed scores in all six categories of the Harter Profile increased, indicating that the pogo stick intervention elicited improved self-esteem in the children. Results from these two pilot studies using pogo sticks in different cohorts of children indicate that pogo-based programs can provide physical and mental health benefits.
\end{abstract}

Keywords: Pogo; Vigorous Physical Activity; Children; Self-Esteem

\section{Introduction}

Most children in Canada (Colley et al., 2011) and the USA (Troiano et al., 2008) do not participate in enough moderate to vigorous physical activity (MVPA) to meet their national guidelines for health benefits. Furthermore, participation in MVPA by children has declined in the past decade (Thompson, McHugh et al., 2009). Meanwhile, the proportion of overweight and obese children and young adults has climbed in parallel with this decline in metabolic stimulation in both Canada (Janssen, Shields, Craig, $\&$ Tremblay) and the USA (Belcher et al., 2010; Flegal, 2005). More MVPA performed weekly would increase energy expenditure and could help to reverse the current epidemic of obesity.

The decline in MVPA is significantly greater in girls than boys (Perry, Rosenblatt, \& Wang, 2004), with girls spending an average of $30 \%$ less time exercising than their male counterparts (Loucaides, Plotnikoff, \& Bercovitz, 2007; Kelley, 1995). Vigorous exercise is particularly low in participation rates by children, especially girls (Craig, Goldberg, \& Dietz, 1996; Thompson, Campagna et al., 2009). Further, the decline in participation by the non-sports active children and children who are less able to access community PA programs is of considerable concern. Girls in lower socioeconomic neighborhoods typically have higher BMIs than do girls from more affluent neighborhoods (Voorhees et al., 2009). Additionally, girls often prefer physical activities that are not similar to traditional team sports, such as bicycling, dancing, rope-jumping, and active games (Sherwood et al., 2003). Giving that enjoyment is the only consistent predictor of physical activity levels in youth (DiLorenzo, Stucky-Ropp, Vander Wal, \& Gotham, 1998), adding more opportunities to participate in physical activities that children and especially girls com- monly view as fun is likely to increase the total weekly time spent doing MVPA.

Self-perception and confidence may strongly influence participation in physical activity (Craig et al., 1996). High self-esteem is associated with increased well-being, social relationships, and academic achievement (DiLorenzo et al., 1998); (Trzesniewski, Donnellan, \& Robins, 2003). Indeed, self-efficacy and the perception of sport competence are among the most important correlates of physical activity for female youth (Loucaides et al., 2007). Youth who participate in sports report significantly higher levels of perceived athletic competence, behavioral competence, social competence and global self-worth (Donaldson \& Ronan, 2006). Physical self-concept may result from perceptions of sporting competence, enjoyment, and physical attractiveness (Ommundsen \& Vaglum, 1997). Successful physical activity programs enhance self-esteem (Faulkner et al., 2007), which is important in adolescents, who often experience drastic changes in self-esteem (Biro, Striegel-Moore, Franko, Padgett, \& Bean, 2006). On the other hand, physical inactivity is associated with low self-esteem, early sexual activity, depression, and poor academic outcomes (Aarnio, Winter, Kujala, \& Kaprio, 2002).

We had offered pogo sticking sessions to a local elementary school in an upper middle class neighborhood and found that the children were highly engaged in these sessions, which resulted in a high level of exertion. However, approximately $10 \%$ of the children, most often those with the highest weight to height ratio, experienced difficulty in mastering the skill involved and seemed more discouraged at their ineptness in view of their classmates' abilities. Based on these observations, we hypothesized that an after school pogo stick program would be 
acceptable to children and that the program would increase several parameters of fitness in children. This study will be referred to as Study 1. In addition, we hypothesized that a pogo stick program adapted for physically inactive girls in a low socioeconomic neighborhood would improve their self-esteem and overall amount of physical activity. This study will be referred to as Study 2. Both studies were approved by a research ethics committee at Dalhousie University. Informed written consent was obtained from a parent or guardian of each subject prior to baseline testing.

\section{Methods: Study 1}

\section{Participants}

Subjects were recruited for this study by posters at several local elementary schools. They were eligible for inclusion if they weighed $36-73 \mathrm{~kg}(80-160 \mathrm{lb})$, were $10-13$ years of age, were willing to wear a protective helmet and were free from injury or illness. A Flybar Foam Master pogo stick was provided for each subject and each child provided his or her own helmet and suitable footwear.

\section{Study Design}

This study was a 6 week intervention using single subject design. Pogo stick sessions one hour long were held after school in a university gymnasium in the winter Monday and Thursday for six consecutive weeks. The location was within walking distance to 3 elementary schools.

\section{Experimental Measurements}

The height and weight of the participants were measured during the baseline testing session using a stadiometer (Detecto, Webb City, Missouri). Aerobic capacity was measured using Leger's 20 m shuttle run test (Leger, Mercier, Gadoury, \& Lambert, 1988). Balance was measured using a stabilometer (Lafayette Instruments Co., Lafayette, Indiana) set to allow 12 degrees of motion in either direction. After an initial trial to become familiar with the mobile platform, each subject attempted to keep the platform horizontal. Three consecutive trials of 20 seconds were performed; the time within each trial for which the subject could remain within 12 degrees of horizontal was recorded and the mean of the time spent balanced for the three trials was calculated. Leg power was determined by from the jump height using a Vertec vertical jump tester (SENOH: Sports Imports, Columbus, OH). Peak leg power was calculated from the best of 3 squat jumps using the following equation (Sayers, Harackiewicz, Harman, Frykman, \& Rosenstein, 1999):

Peak Power $(\mathrm{W})=60.7 \times$ jump height $(\mathrm{cm})+45.3 \times$ body mass $(\mathrm{kg})-2055$.

Subjects also completed a questionnaire that asked how often and for how long they participated in sports, exercise, or games that make them sweat, which activities these were, whether these sports or physical activities took place during school or after school. Sections of the questionnaire pertained to their experience with activities requiring proficiency in either balance or bouncing. Attendance was recorded at the six weeks of pogo stick sessions, and a log kept of which games or activities were played and requested each day. All measurements made at baseline were repeated after the six weeks of the pogo stick intervention.

\section{Study Procedures}

The intervention was divided into a one week skill acquisition phase and a five week pogo activity phase. The skill acquisition phase was designed to give the subjects individualized attention while learning how to bounce on the pogo sticks. To enable rapid mastery of pogo sticking, the subject to supervisor ratio was 2:1 during these first two sessions. The final five weeks of the program were designed to promote fun through a wide variety of games and activities that progressed in level of challenge. The children were encouraged to propose which activities they would like to try while on pogo sticks and to express which ones they wished to repeat. The researchers and volunteers facilitated the sessions but did not participate on the pogo sticks except for initial demonstrations.

\section{Data Analysis}

All analyses were performed with SPSS version 15.0. Preand post-intervention measures were compared using a 2-way analysis of variance with repeated measures with differences accepted as significance at $\mathrm{p} \leq 0.05$. Due to the small sample size, trends $(0.1>p>0.05)$ were also reported. Data from the questionnaire, including current physical activity level and prior activities requiring proficiency in balance were coded as moderate or vigorous physical activities based on published categorizations (Ainsworth et al., 1993; Ainsworth et al., 2000) and analyzed for relationships using the Pearson's correlation test.

\section{Results: Study 1}

Nine healthy children ( 7 boys) aged 10 - 11 years volunteered to take part in this study. Children were recruited without selection by sex. Subject characteristics are shown in Table 1. The subjects' attendance averaged $82 \%$, including attendance during two storm days when school was cancelled due to adverse weather conditions. The means of the data for boys was compared to that of the girls and it did not differ by visual or statistical inspection. Therefore, data from boys and girls was combined and analyzed together. Although the height of the children increased following the six week intervention period ( $p$ $=0.03$ ), no other characteristic had changed significantly at the post-intervention testing. A total of 13 sport-like activities were tried, with 6 of these repeated due to multiple requests from participants. These 6 activities were jump rope, high jump, catch, basketball, dodgeball, and an obstacle course, some of which were performed partially hands free. Two children suffered injuries; one was a blister from a rub by knee pads worn due to gripping the pogo stick while performing hands free, and the other was from a fall which caused a sore wrist that was not sufficiently sore to stop the child from continuing to participate in that session.

Following the six week intervention, balance on the stabilometer increased by $19 \%(p=0.001)$. See Table 2 . No other fitness measure differed significantly from baseline measures. Leg power was significantly correlated to total time currently engaged in moderate to vigorous physical activities $(r=0.81, p$ $<0.05$ ). Relative $\mathrm{VO}_{2}$ max was strongly correlated to time currently spent doing vigorous activity $(\mathrm{r}=0.89, \mathrm{p}<0.01)$ and correlated to total time spent in all moderate to vigorous physical activity $(\mathrm{r}=0.73, \mathrm{p}<0.05)$. Neither prenor post-intervention balance was correlated with time spent in physical activity $(\mathrm{r}=0.05)$. 
Table 1.

Subject characteristics.

\begin{tabular}{cccc}
\hline Characteristic & $\begin{array}{c}\text { Baseline } \\
(\text { mean } \pm \text { SD })\end{array}$ & $\begin{array}{c}\text { Post-intervention } \\
(\text { mean } \pm \text { SD) }\end{array}$ & p-value \\
\hline $\mathrm{n}$ (boys, girls) & $9(7,2)$ & $9(7,2)$ & \\
Age $(\mathrm{y}) ;(\mathrm{n})$ & $10(5) ; 11(4)$ & $10(4) ; 11(5)$ & \\
Height $(\mathrm{cm})$ & $149.2 \pm 7.7$ & $150.8 \pm 7.6$ & 0.03 \\
Weight $(\mathrm{kg})$ & $43.8 \pm 7.4$ & $44.4 \pm 7.9$ & $\mathrm{NS}$ \\
BMI $\left(\mathrm{kg} / \mathrm{m}^{2}\right)$ & $19.5 \pm 2.2$ & $19.4 \pm 2.1$ & $\mathrm{NS}$ \\
\hline
\end{tabular}

Abbreviations: $\mathrm{n}=$ number of subjects; $\mathrm{NS}=\mathrm{p}>0.1$.

Table 2.

Fitness parameters.

\begin{tabular}{cccc}
\hline Fitness measure & $\begin{array}{c}\text { Baseline } \\
(\text { mean } \pm \mathrm{SD})\end{array}$ & $\begin{array}{c}\text { Post-intervention } \\
(\text { mean } \pm \mathrm{SD})\end{array}$ & p-value \\
\hline Balance (s) & $12.28 \pm 3.42$ & $14.65 \pm 3.31$ & 0.001 \\
Leg Power $(\mathrm{W})$ & $1818.4 \pm 496.1$ & $1765.0 \pm 520.4$ & $\mathrm{NS}$ \\
$\begin{array}{c}\text { Relative } \mathrm{VO}_{2} \max \\
(\mathrm{ml} / \mathrm{kg} / \mathrm{min})\end{array}$ & $49.3 \pm 4.8$ & $49.6 \pm 4.9$ & $\mathrm{NS}$ \\
$\begin{array}{c}\text { Absolute } \\
\mathrm{VO}_{2} \max (\mathrm{L} / \mathrm{min})\end{array}$ & $1.15 \pm 0.22$ & $1.18 \pm 0.22$ & $\mathrm{NS}$ \\
\hline
\end{tabular}

\section{Methods: Study 2}

\section{Participants}

Girls who were 10 - 13 years old, weighed 36 - $72 \mathrm{~kg}$ (80 $160 \mathrm{lb}$ ) due to weight restrictions provided by the pogo stick manufacturers, were not injured or ill, and lived in a specific low socioeconomic inner city area of North Halifax were recruited to participate in this study. Flybar Foam Master pogo sticks and helmets approved by the Canadian Standards Association were provided for each subject; participants were required to dress in athletic apparel and wear rubber-soled gymshoes to all activity sessions. No injuries were sustained by the children in this program.

\section{Study Design}

This pilot study was a 6 week cohort intervention using single subject design (Janosky, 2005). The hour long pogo stick sessions were held in the winter after school twice a week for six consecutive weeks. The location used was a dance studio in the basement of a local community center that was within walking distance to an elementary school.

\section{Experimental Measurements}

Each child's self-esteem was assessed using a questionnaire, the Harter Self-Perception Profile for Children (Wichstrom, 1995). Participants were given privacy and space from each other during test administration. Talking among participants was not permitted. Test administrators were instructed to answer any questions using the directions set forth by the Harter Scale (Wichstrom, 1995). The children took approximately 25 minutes to complete this instrument.

To determine if the pogo intervention correlated with a change in overall PA, subjects were instructed to wear a Steps Count pedometer at all times except when sleeping, swimming or bathing. Each pedometer was marked with a number code, which was matched to the participant and was reset immediately before being secured on a subject. Pedometers were sealed using $3 \mathrm{M}^{\mathrm{TM}}$ Steri-Strip $^{\mathrm{TM}}$ Adhesive Skin Closures sized 1/8 inch by 3 inch to ensure they remained sealed for the duration of each test. These closures allowed for a visual detection of pedometers that had been opened without providing extra weight or size to the instrument. Participants did not have access to their individual or measures. Immediately prior to the study, each pedometer was tested for accuracy under conditions of walking, jogging, and pogo sticking.

\section{Experimental Procedures}

The program was divided into two phases, the first one 2 weeks long and the second one, 4 weeks. In the first phase, the girls were encouraged to increase their number of consecutive jumps, jump on a spot, jump linearly by following line markings on the floor, and then to jump forwards, backwards, left, and right. During the second phase, they worked on jumping controlled distances, with eyes fixed on a target at eye level, in small circles, and to music without getting distracted. They also practiced bouncing at faster and slower rates and in unison with a partner. Finally, they combined shorter moves into longer sequences and practiced choreographed formations as a whole group. Each session included an aerobic warm up, stretching and various structured activities. Music to be played during each session was chosen through group consensus and played at a volume that did not compromise verbal communication between participants. Personal music devices were not permitted. All sessions were structured and facilitated by the principle investigator. A volunteer to participant ratio was maintained at 1:4 or smaller. Student volunteers were recruited from the Kinesiology program at Dalhousie University.

\section{Data Analysis}

If a participant missed more than 2 sessions or failed to complete either the pre- or post-test measures her data was not included in the analysis. The primary determinant as to the usefulness of this intervention is identified a priori as improvement in the majority of participants' scores on the Harter Self-Perception Profile and the number of steps taken daily as collected by the pedometers. Pre- versus post-program measures were compared using a 2-way analysis of variance with repeated measures computed using SPSS version 15.0. Statistical significance was set at the alpha level of 0.05 although, due to the small sample size, trends $(0.1>\mathrm{p}>0.05)$ were also reported.

\section{Results: Study 2}

The children in this study were not physically measured but 3 out of the 7 whose data was analyzed appeared to be obese, 2 appeared possibly overweight, while 2 were slim. Out of a total of twelve pogo sessions, four participants were $100 \%$ compliant, two participants were $92 \%$ compliant with one missed session, and one individual was $83 \%$ compliant. Another subject was $75 \%$ compliant, having missed three sessions. Data from the subject who missed three sessions were omitted from both the pedometer count and the Harter Self-Perception Profile scores because it exceeded the 2 missed sessions cutoff. All participants strongly expressed that the program was fun and that they felt an attachment to the program. Due to the strength of the demand, the program was subsequently locally funded so that it could continue to 
be offered in North Halifax and opened to additional girls. An additional observation was that each girl quickly developed an attachment to "her" pogo stick and helmet and created clear methods to distinguish her own equipment from the rest.

The Harter Self-Perception Profile was administered at the same time during the first day of the intervention and the last day of the intervention. Seven participants were eligible to complete the post-test measures. All results were segregated according to the six subscales: scholastic competence (SCS), social acceptance (SAS), athletic competence (ACS), physical appearance (PAS), behavioral conduct (BCS), and global self-worth (GSW). Percent differences in scores categorized by domain illustrate the magnitude of change between pre- and post-test administration (Figure 1). These differences were significant at an alpha level 0.05 in the behavioral conduct scale. Although not significant, a trend was found in the score increase in the global self-worth scale.

The mean number of steps taken by the 7 girls doubled from $3302 \pm 1035$ before the study to $6821 \pm 8497$ in the final week of the intervention. However, due to large differences between subjects, this increase was not significant.

\section{Discussion}

Both studies demonstrated that pogo exercise was fun for pre-teen children whether they were previously sports-active or sedentary. It also provided a considerable amount of high intensity interval type exercise, as demonstrated by an observed rapid onset of sweating, flushed faces, and frequent water fountain breaks in both groups. Balance, but not other fitness measures, increased in the active children and steps taken daily doubled in the sedentary girls. Substantial increases in selfesteem were measured in the sedentary girls from the low socioeconomic neighborhood.

To our knowledge, this is the first study to investigate benefits to youth of exercise using pogo sticks. However, Colon et al. (Colin, Stephens, Graman, \& Kues, 1984) anecdotally reported an increase in balance, which is supported by the results of Study 1. Interestingly, in our study, balance prior to the intervention was not correlated to time spent in MVPA. This suggests that balance does not improve with all physical activity, but only with training that is specific to balance. A previous study increased balance in youth with the intent of reducing sport-related injury by utilizing wobble boards as part of a proprioceptive balance training intervention (Emery, Cassidy, Klassen, Rosychuk, \& Rowe, 2005). That the pogo stick intervention was able to improve balance suggests that pogo sticking may be a fun method to improve balance.

Cardiovascular fitness did not increase as expected following the pogo stick intervention, perhaps because these children were already physically active and healthy. They had an average $\mathrm{VO}_{2}$ max of $49.3 \mathrm{ml} / \mathrm{kg} / \mathrm{min}$ before they began the pogo stick intervention, which is consistent with the findings of others who reported that the average aerobic capacity of youth aged 10 - 12 was 52.5 ml $/ \mathrm{kg} / \mathrm{min}$ (Frost, Bar-Or, Dowling, \& Dyson, 2002). However, we are somewhat uncertain about the accuracy of our results from the Leger shuttle test, given that the children did not enjoy this test and appeared to drop out of it before they had applied their maximal effort.

Diallo and colleagues (Diallo, Dore, Duche, \& Van Praagh, 2001) reported that plyometric training improved leg power in boys 12 - 13 years old, who were slightly older than our cohort.

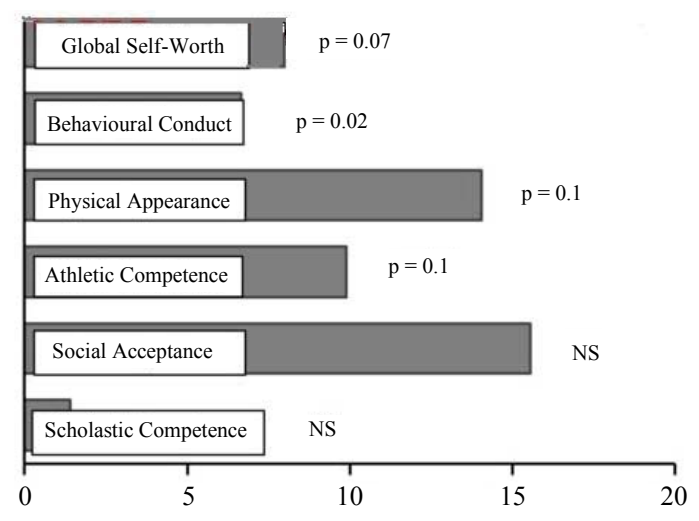

Figure 1.

Summary of percent differences in scores between pre- and post-test administration of the Harter Self-Perception Profile for children, categorized by domain.

However, leg power did not improve with pogo sticking in our group nor in a cohort of pogo stickers reported by Colin and colleagues (Colin et al., 1984). They attributed their finding to reduced knee flexion, which they limited to 5 - 7 degrees of flexion as an intervention condition. Knee flexion was not measured in our study, although we observed that as the subjects became more efficient, they required less knee flexion to produce the desired movement. While plyometric activities produce increases in leg power, more efficient but less dynamic bounces on the pogo stick may not. These less dynamic movements may not have been sufficient to produce increased leg power to the same extent as does plyometric training.

Self-evaluative judgments become less positive as children move into adolescents which is evident as the self-esteem of girls often markedly declines between the ages of 10 and 13 years old (Brown et al., 1998). Because low self-esteem may increase the risk of harmful behavior (Biro et al., 2006) the efficacy of physical activity to raise self-esteem in children (Inchley, Kirby, \& Currie, 2011) is especially important. The Harter Profile behavioral conduct domain assesses factors internal to the individual such as skills, willpower, and knowledge, as well as external factors such as cooperation. During the course of the pogo program behavioral conduct scores significantly improved. The observed increase may be explained by the discipline needed to learn a new skill such as pogo sticking. Pogo sticking requires considerable balance and proved quite difficult for some participants to learn. Although we did not measure skill progression in the participants, our observations were that certain participants seemed to pick up the skills quickly while others experienced considerable difficulty at the beginning of the program. All participants displayed perseverance and challenge during the sessions but it was particularly evident in the individuals who experienced marked difficulty. By the end of the second week of the program all participants had made significant improvements in their skill levels and by the end of the program everyone had mastered the pogo stick. Cooperation was also promoted through teambuilding activities and group choreographed pogo dance projects. The improvement in behavioral conduct is positive because the perception of behavioral control is linked with intent to participate in vigorous physical activity in children (Craig et al., 1996). This suggests that when children feel competent with their physical activity abilities they are more likely to become 
engage in physical activities and sustain participation. For this reason, the Harter scale is able to illustrate certain aspects of self-concept that are beneficial to participation in physical activity (Donaldson \& Ronan, 2006) and may suggest that attitudes towards physical activity had improved in our subjects.

The global self-worth of the pogo program participants improved as an overall trend. The global self-worth domain is intended to highlight how much the individual likes herself as a person so the marked improvement on this subscale may also influence improvement in other domains. However, the stability of these results depends on if global self-worth is considered a stable concept or an evolving characteristic that changes in response to developmental changes (Granleese \& Joseph, 1994). Due to the controversy of the formulation and consistency of this concept it is difficult to draw conclusions based on increases in this scale alone although when combined with the observed increases in the other five domains, we are confident with the positive impact of the pogo program. Based on the ability of the pogo program to elicit increases in the global self worth domain after six weeks, we assume that this global self worth can reflect short-term fluctuations in self-esteem (Harter \& Whitesell, 2003).

The high variability in the step counts recorded by the pedometers rendered at least one very high value in the post-pogo measures to be suspect and, therefore, the overall post-pogo mean to be higher than its true values. However, without evidence that it and not others should be discarded, the mean counts were computed using all data. The mean values of the pedometer counts indicate that the girls in the low socioeconomic neighborhood averaged just over half the steps taken by girls in other western countries at the end of the intervention and a mere quarter of the average number prior to the pogo training. Given the rapid recent increase in obesity among children (Shields \& Tremblay, 2010), this low level of physical activity is alarming.

Limitations of these pilot studies include their small number of subjects and the lack of control groups. We found it difficult to recruit children for the control groups because they all wished to pogo. Additionally, we are not entirely confident in the results of the Leger $20 \mathrm{~m}$ test and the pedometer data. Some children found the Harter Self-Perception Profile for Children to be long and complicated and may not have retained enough focus to complete the test to the best of their abilities. Pogo sticking is very strenuous, so the hour-long format of both interventions might not be optimal. Instead, bouts of 10 minutes once or twice a day, perhaps at recess, might be more effective in delivering bouts of high intensity interval like exercise. Such exercise has been shown to be more motivating to children (Barkley, Epstein, \& Roemmich, 2009) and can provide substantial health benefits to some adolescents (Tjonna et al., 2009).

In conclusion, we tested two different exercise interventions by offering them as after school programs to two different cohorts of elementary school aged children. Both programs utilized pogo sticks and were adapted for their targeted populations. All the children in both studies expressed enthusiasm for the pogo programs and were able to gain the skills needed to remain on a pogo stick until volitional dismount. The results and observations from this study suggest that pogo stick programs could provide substantial amounts of vigorous exercise to a cross-section of children and may be especially useful in providing both psychosocial and physical benefits to sedentary girls in low socioeconomic neighborhoods.

\section{Acknowledgements}

The authors would like to thank Flybar and SBI Enterprises for the donation of the pogo sticks used in the study.

\section{REFERENCES}

Aarnio, M., Winter, T., Kujala, U., \& Kaprio, J. (2002). Associations of health related behaviour, social relationships, and health status with persistent physical activity and inactivity: A study of Finnish adolescent twins. British Journal of Sports Medicine, 36, 360-364. doi: 10.1136/bjsm.36.5.360

Ainsworth, B. E., Haskell, W. L., Leon, A. S., Jacobs, D. R. Jr., Montoye, H. J., Sallis, J. F. et al. (1993). Compendium of physical activities: Classification of energy costs of human physical activities. Medicine and Science in Sports and Exercise, 25, 71-80. doi:10.1249/00005768-199301000-00011

Ainsworth, B. E., Haskell, W. L., Whitt, M. C., Irwin, M. L., Swartz, A. M., Strath, S. J. et al. (2000). Compendium of physical activities: An update of activity codes and MET intensities. Medicine and Science in Sports and Exercise, 32, S498-504. doi:10.1097/00005768-200009001-00009

Barkley, J. E., Epstein, L. H., \& Roemmich, J. N. (2009). Reinforcing value of interval and continuous physical activity in children. Physiology \& Behavior, 98, 31-36. doi:10.1016/j.physbeh.2009.04.006

Belcher, B. R., Berrigan, D., Dodd, K. W., Emken, B. A., Chou, C. P., \& Spruijt-Metz, D. (2010). Physical activity in US youth: Effect of race/ethnicity, age, gender, and weight status. Medicine and Science in Sports and Exercise, 42, 2211-2221. doi:10.1249/MSS.0b013e3181e1fba9

Biro, F. M., Striegel-Moore, R. H., Franko, D. L., Padgett, J., \& Bean, J. A. (2006). Self-esteem in adolescent females. The Journal of Adolescent Health, 39, 501-507. doi:10.1016/j.jadohealth.2006.03.010

Brown, K. M., McMahon, R. P., Biro, F. M., Crawford, P., Schreiber, G. B., Similo, S. L. et al. (1998). Changes in self-esteem in black and white girls between the ages of 9 and 14 years. The NHLBI Growth and Health Study. The Journal of Adolescent Health, 23, 7-19. doi:10.1016/S1054-139X(97)00238-3

Colin, V., Stephens, W., Graman, P., \& Kues, J. (1984). The pogo stick as an adjunct in the knee rehabilitation of athletes. Physician and Sportsmedicine, 12, 59-64.

Colley, R. C., Garriguet, D., Janssen, I., Craig, C. L., Clarke, J., \& Tremblay, M. S. (2011). Physical activity of Canadian children and youth: Accelerometer results from the 2007 to 2009 Canadian Health Measures Survey. Health Report, 22, 15-23.

Craig, S., Goldberg, J., \& Dietz, W. H. (1996). Psychosocial correlates of physical activity among fifth and eighth graders. Preventive Medicine, 25, 506-513. doi:10.1006/pmed.1996.0083

Diallo, O., Dore, E., Duche, P., \& Van Praagh, E. (2001). Effects of plyometric training followed by a reduced training programme on physical performance in prepubescent soccer players. Journal of Sports Medicine and Physical Fitness, 41, 342-348.

DiLorenzo, T. M., Stucky-Ropp, R. C., Vander Wal, J. S., \& Gotham, H. J. (1998). Determinants of exercise among children. II. A longitudinal analysis. Preventive Medicine, 27, 470-477. doi:10.1006/pmed.1998.0307

Donaldson, S. J., \& Ronan, K. R. (2006). The effects of sports participation on young adolescents' emotional well-being. Adolescence, 41, 369-389.

Emery, C. A., Cassidy, J. D., Klassen, T. P., Rosychuk, R. J., \& Rowe, B. H. (2005). Effectiveness of a home-based balance-training program in reducing sports-related injuries among healthy adolescents: A cluster randomized controlled trial. CMAJ, 172, 749-754. doi: $10.1503 / \mathrm{cmaj} .1040805$

Faulkner, G. E., Adlaf, E. M., Irving, H. M., Allison, K. R., Dwyer, J. J., \& Goodman, J. (2007). The relationship between vigorous physical activity and juvenile delinquency: A mediating role for self-esteem? Journal of Behavioral Medicine, 30, 155-163. doi:10.1007/s10865-006-9091-2

Flegal, K. M. (2005). Epidemiologic aspects of overweight and obesity 
in the United States. Physiology \& Behavior, 86, 599-602. doi:10.1016/j.physbeh.2005.08.050

Frost, G., Bar-Or, O., Dowling, J., \& Dyson, K. (2002). Explaining differences in the metabolic cost and efficiency of treadmill locomotion in children. Journal of Sports Sciences, 20, 451-461. doi:10.1080/02640410252925125

Granleese, J., \& Joseph, S. (1994). Reliability of the Harter Self-Perception Profile for children and predictors of global self-worth. The Journal of Genetic Psychology, 155, 487-492. doi: $10.1080 / 00221325.1994 .9914796$

Harter, S., \& Whitesell, N. R. (2003). Beyond the debate: Why some adolescents report stable self-worth over time and situation, whereas others report changes in self-worth. Journal of Personality, 71, 1027-1058. doi:10.1111/1467-6494.7106006

Inchley, J., Kirby, J., \& Currie, C. (2011). Longitudinal changes in physical self-perceptions and associations with physical activity during adolescence. Pediatric Exercise Science, 23, 237-249.

Janosky, J. E. (2005). Use of the single subject design for practice based primary care research. Postgraduate Medical Journal, 81, 549-551. doi:10.1136/pgmj.2004.031005

Janssen, I., Shields, M., Craig, C. L., \& Tremblay, M. S. (2011). Prevalence and secular changes in abdominal obesity in Canadian adolescents and adults, 1981 to 2007-2009. Obesity Reviews, 12, 397-405. doi:10.1111/j.1467-789X.2010.00815.x

Kelley, G. A. (1995). Gender differences in the physical activity levels of young African-American adults. Journal of the National Medical Association, 87, 545-548.

Leger, L. A., Mercier, D., Gadoury, C., \& Lambert, J. (1988). The multistage 20 metre shuttle run test for aerobic fitness. Journal of Sports Science, 6, 93-101.

Loucaides, C. A., Plotnikoff, R. C., \& Bercovitz, K. (2007). Differences in the correlates of physical activity between urban and rural Canadian youth. Journal of School Health, 77, 164-170. doi:10.1111/j.1746-1561.2007.00187.x

Ommundsen, Y., \& Vaglum, P. (1997). Competence, perceived importance of competence and drop-out from soccer: A study of young players. Scandinavian Journal of Medicine \& Science in Sports, 7, 373-383. doi:10.1111/j.1600-0838.1997.tb00170.x

Perry, A. C., Rosenblatt, E. B., \& Wang, X. (2004). Physical, behavioral, and body image characteristics in a tri-racial group of adoles- cent girls. Obesity Research, 12, 1670-1679.

doi:10.1038/oby.2004.207

Sayers, S. P., Harackiewicz, D. V., Harman, E. A., Frykman, P. N., \& Rosenstein, M. T. (1999). Cross-validation of three jump power equations. Medicine and Science in Sports and Exercise, 31, 572-577. doi:10.1097/00005768-199904000-00013

Shields, M., \& Tremblay, M. S. (2010). Canadian childhood obesity estimates based on WHO, IOTF and CDC cut-points. International Journal of Pediatric Obesity, 5, 265-273. doi: $10.3109 / 17477160903268282$

Thompson, A. M., Campagna, P. D., Durant, M., Murphy, R. J., Rehman, L. A., \& Wadsworth, L. A. (2009). Are overweight students in Grades 3, 7, and 11 less physically active than their healthy weight counterparts? International Journal of Pediatric Obesity, 4, 28-35. doi: $10.1080 / 17477160802170050$

Thompson, A. M., McHugh, T. L., Blanchard, C. M., Campagna, P. D., Durant, M. A., Rehman, L. A. et al. (2009). Physical activity of children and youth in Nova Scotia from 2001/02 and 2005/06. Preventive Medicine, 49, 407-409. doi:10.1016/j.ypmed.2009.09.009

Tjonna, A. E., Stolen, T. O., Bye, A., Volden, M., Slordahl, S. A., Odegard, R. et al. (2009). Aerobic interval training reduces cardiovascular risk factors more than a multitreatment approach in overweight adolescents. Clinical Sciences (Lond), 116, 317-326. doi: $10.1042 / \mathrm{CS} 20080249$

Troiano, R. P., Berrigan, D., Dodd, K. W., Masse, L. C., Tilert, T., \& McDowell, M. (2008). Physical activity in the United States measured by accelerometer. Medicine and Science in Sports and Exercise, 40, 181-188.

Trzesniewski, K. H., Donnellan, M. B., \& Robins, R. W. (2003). Stability of self-esteem across the life span. Journal of Personality and Social Psychology, 84, 205-220. doi:10.1037/0022-3514.84.1.205

Voorhees, C. C., Catellier, D. J., Ashwood, J. S., Cohen, D. A., Rung, A., Lytle, L. et al. (2009). Neighborhood socioeconomic status and non school physical activity and body mass index in adolescent girls. Journal of Physical Activity \& Health, 6, 731-740.

Wichstrom, L. (1995). Harter's Self-Perception Profile for adolescents: Reliability, validity, and evaluation of the question format. Journal of Personality Assessment, 65, 100-116. doi: $10.1207 / \mathrm{s} 15327752$ jpa6501_8 